\title{
Design of an Improve Guardrail for Metro Manila South Super Skyways using Steel and Rubber Tires
}

\author{
Dr. Noel Hugo D. Binag \\ Associate Professor \\ College of Engineering and Industrial Technology \\ Rizal Technological University, Philippines
}

\begin{abstract}
This study is to introduce a design of an improve guardrail using a combined steel and scrap rubber tire materials as an alternative guardrails for the existing steel guardrails in Metro Manila South Super Skyway which cause several accidents in the past years. Guardrail is a system designed to keep people or vehicles from straying into dangerous or off-limits areas. In the existing skyway roads, the guardrails are steel metal bar along the sides that prevent vehicles and people from falling off. Based on researcher's inspection of the existing guardrails, it showed that transport facilities were not safe enough to protect riding vehicles. Several accidents were experienced in the Skyway during the past years. Accordingly, the height of the existing guardrail is lower than one meter which does not follow the International Standards of at least $1.5 \mathrm{~m}$ minimum heights. Thus, there is a need to design a guardrail that is safe enough for the people and the riding vehicles. Using new rubber for guardrails to augment the steel is found to be of great help to improve the safety in the skyway. It is known that rubber has lesser impact and damage to contacted object thus, the design provides sliding force through the established rubber components that make safer. The study used the ergonomic research or the human factors research which is the practice of designing products, systems or processes to take proper account to optimize human well-being and overall system performance. It is employed to fulfill the goals of occupational health, safety and productivity. Furthermore, the study also considered the comparison of the properties of materials. As such, it is hereby concluded that there is a need for the improvement of the existing guardrails. Hence, this design was produced as basis for the rehabilitation of the existing skyway guardrails.
\end{abstract}

Keywords-Guardrails, rubber, tires, steel, accident, skyway.

\section{INTRODUCTION}

The Metro Manila South Super Skyway is one of the longest flyovers in the world with a total length of 19.4 miles (31.2 kilometers). It was generally observed that driving at top speed along these flyovers especially during rainy season where roads become so slippery that risk travellers especially motorist.
The skyway is a fully grade elevated highway and motorway separately serving as the main expressway in southern parts of Metro Manila crossing over the existing South Luzon Expressway. It stretches in Gil Puyat Avenue in the north to Alabang-Zapote Road in the south and crosses through the highly urbanized areas of Makati, Pasay, Taguig, Parañaque, and Muntinlupa, relieving the SLEX and other major thoroughfares from heavy traffic.

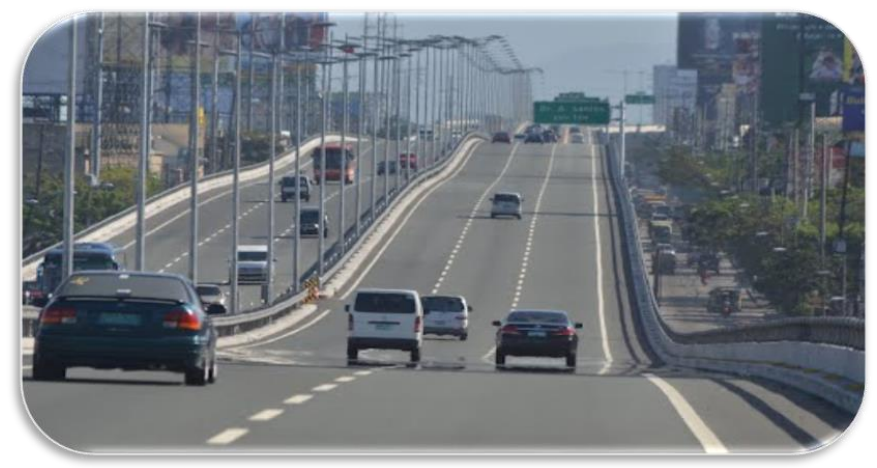

Figure 1. Metro Manila South Super Skyways

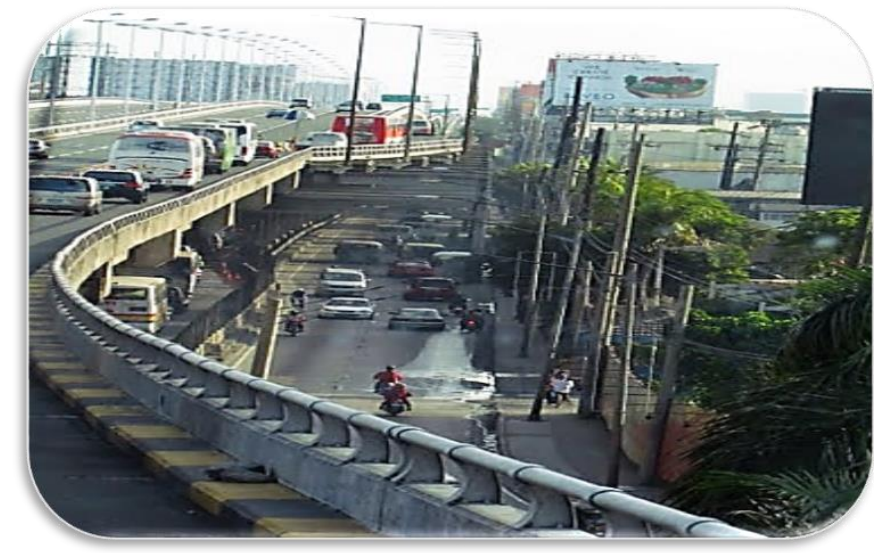

Figure 2.Metro ManilaSouth Super Skyway Guardrails

According to (Zurbano, 2016) [1], 50 roads in National Capital Region have been identified as accident prone areas by the Metro Manila Development Authority. Such as Sen. Gil Puyat Avenue in Makati, Alabang-Zapote Road, and Pres. Sergio Osmeña Highway where the elevated highway (Skyway) currently stretches belongs to the list of these roads in the southern part of Metro Manila. 
Several accidents were experienced in the Skyway. On July 2011 the Dimple Star Transport bus fell from the Skyway ramp along the South Luzon Expressway (SLEX) in Paranaque City plunged about 40 feet down at the Sucat West Service Road in Marcelo Green Village. On December 16, 2013, the Don Mariano Transit fell off the Skyway leaving 21 persons dead. Accordingly, the height of the existing guardrail is lower than one meter which does not follow the International Standards of at least $1.5 \mathrm{~m}$ minimum heights.

In the Philippine Daily Inquirer by Brizuela, M. B. [2], it was reported that there are two consecutive accidents happened in July 2015 that raised concerns over safety standards implemented on the expressway. Mitsubishi Strada pickup nearly fell off the Skyway when it breached the railing between the South Luzon Expressway's Bicutan and Sucat exits in Parañaque. More than a week after half of a Mitsubishi Strada pickup hanged over the edge of the Skyway near the Bicutan exit, a sports utility vehicle plunged more than 10 meters near the same spot of the main expressway and fell on a concrete wall along the East Service Road in Taguig City. Another vehicle was speeding along the Skyway and the driver lost control of the vehicle causing him to hit the rail before falling off the highway.

Roadside Safety Engineers design the safest economical hardware able to absorb large amounts of energy and safely contain the impacted vehicle. This system is complex that it involves dynamic loading, very large deformations, material failure and nonlinear elastic material. The existing guardrails installed in Skyway Paranaque was made up of steel and concrete with an elevation of approximately seven-hundred millimeters but was not able to safeguard the motorists. In this case other materials should be considered to develop an effective guardrail to avoid accidents.

Rubber tires are among the largest and most problematic sources of waste due to the large volume produced. By developing strategies, recycling tires to be developed as guardrails may be of great help to solve the problem.

The study used the ergonomic research or the human factors research which is the practice of designing products, systems or processes to take proper account of the interaction between them and the people who use them in order to optimize human well-being and overall system performance. It is employed to fulfill the goals of occupational health, safety and productivity.

\subsection{Guardrails}

Guardrails are used to shield motorists from a wide variety of roadside hazards, including point hazards (such as a bridge pier or utility pole), medium-sized hazards (such as roadside culverts), and long hazards (such as steep roadside slopes) (Gabler,H.C.et.al., 2007)[3].

Mechanical properties may be used as a metric by which the benefits of one material versus another can be assessed. Here are some common properties that consider the strength of a material such as tensile strength, elongation, shear, thermal conductivity, young's modulus of elasticity and hardness.

\subsection{Rubber}

Rubber is a universally used commodity in our everyday lives. According to Burton (1949)[4] that for practical purposes "rubber" may be defined as a material that is capable of being stretched or otherwise distorted to a considerable extent and then retracting quickly to nearly its original dimensions. We use rubber for industrial applications and household applications. The largest consumers of rubber are tires and tubes, followed by general rubber goods. While according to Blow (1971)[5], rubber belongs to the class of substances termed 'polymers': high molecular weight compounds, predominantly organic, consisting of long-chain molecules made up of repeating units usually on a back bone of carbon atoms.

According to Tangonan (2012)[6], reducing the forces created when one surface comes abruptly into contact with another is one of the fundamental roles performed by cautioning material. The hevea brasiliensis is widely cultured species for the commercial production of natural rubber.

One of the fundamental properties of rubber is elasticity. Rubber is unique in the extent to which it can be extorted, and the rapidity and degree to which it recovers to its original shape and dimension. It is, however, not perfectly elastic. The rapid recovery is not complete. Part of the distortion is recovered more slowly and part is retained. The extent of this permanent distortion, hold permanent set, depends upon the rate and duration of the applied force. The slower the force and the longer that it is maintained, the greater is the permanent set. Because of rubber's elasticity, however, the permanent set may not be complete even after long periods of applied force. This quality is of, obvious value in gaskets and seals.

Kim (2004)[7] stated that rubber is indispensable to a variety of industries and products, and our modern world, with its multifaceted necessities and luxuries, would be unthinkable without it.

\subsection{Tires}

Tires are rubber-made material utilized as a component for vehicles. According to Mark, et al. (2013)[8] that in human history, the wheel is considered one of the most important inventions because it found use in a wide range of applications such as transportation vehicles, construction equipment, and internal parts of machinery. They also stated that geometrically, a tire is a torus. Mechanically, a tire is a flexible, high-pressure container. Structurally, a tire is a highperformance composite built using elastomers, fibers, steel, and a range of organic and inorganic chemicals.

\subsection{Waste Rubber Tires}

Studies show the different methods of reclaiming waste rubber. The common techniques are physical reclaiming process which involves devulcanization of cured rubber using the thermo-mechanical, the cryo-mechanical, the microwave, the ultrasonic treatment, and the mechano-chemical, as well as by chemical method. Waste rubber can be used for reformulation and recurred into new products by using any of these techniques. Different surface modification methods of waste rubber are also employed to improve the chemical interactions of particles by coating only the surface of rubber particles, without breaking the crosslinks of the vulcanized material (Paglicawan, 2004)[9]. 


\section{RESULT AND DISCUSSION}

Table 1 presents the different properties of steel and rubber in terms of hardness, tensile strength, shear, elongation, young's modulus and thermal conductivity.

\section{Table 1}

Comparison of Steel and Rubber In Terms of Hardness, Tensile Strenght, Shear, Elongation, Young's Modulus and Thermal Conductivity.

\begin{tabular}{|l|c|c|}
\hline \multicolumn{1}{|c|}{ Properties } & Steel & Rubber \\
\hline Hardness & $250 \mathrm{HB}$ & $40-90 \mathrm{HB}$ \\
\hline Tensile Strength & $400 \mathrm{MPa}$ & $16 \mathrm{MPa}$ \\
\hline Shear & $80000 \mathrm{MPa}$ & $0.3 \mathrm{MPa}$ \\
\hline Elongation & $10 \%$ & $300-500 \%$ \\
\hline $\begin{array}{l}\text { Young's } \\
\text { Modulus }\end{array}$ & $200000 \mathrm{MPa}$ & $20 \mathrm{MPa}$ \\
\hline $\begin{array}{l}\text { Thermal } \\
\text { Conductivity }\end{array}$ & $52.0 \mathrm{w} / \mathrm{m}-\mathrm{k}$ & $0.17-0.3 \mathrm{w} / \mathrm{m}-\mathrm{k}$ \\
\hline
\end{tabular}

In relation to hardness and tensile strength, the lower value of hardness and tensile strength, the larger impact the material will resist. The rubber has lower values than steel which means rubber has a high resistance to impact. However, rubber needs smaller force before failure takes place.

In terms of shear modulus, the lower value of shear modulus, the more flexible the material is. The rubber has lower shear modulus than steel which means that the rubber is more flexible than steel. However, the rubber needs smaller force for it to show deformation.

As to elongation at break, the higher value of elongation, the longer the material can stretch before it breaks. The percentage of elongation at break at rubber is way higher than the percentage of the steel. This means that rubber can expand up to three to five times of its length rather than the steel that could only expand up to 0.01 of its length before failure takes place.

With regard to young's modulus of elasticity, the greater the resistance to change, the greater the stiffness of the material is. Rubber has lower value of modulus which means it is more flexible than steel.

Finally, as to the thermal conductivity, the modulus increases with temperature which means the rubber gets stiffer slower than steel when increasing environment temperature.

Table 2 shows the comparison of mechanical properties between steel and rubber in terms of impact resistance.

Table 2

Comparison of Properties of Steel and Rubber In terms of Impact Resistance.

\begin{tabular}{|l|c|c|}
\hline \multirow{2}{*}{\multicolumn{1}{|c|}{ Properties }} & \multicolumn{2}{c|}{ Impact Resistance } \\
\cline { 2 - 3 } & Steel & Rubber \\
\hline Hardness & Brittle & Ductile \\
\hline Shear & Brittle & Ductile \\
\hline Tensile & Brittle & Ductile \\
\hline Elongation at Break & Brittle & Ductile \\
\hline Young's Modulus & Brittle & Ductile \\
\hline Thermal Conductivity & Brittle & Ductile \\
\hline
\end{tabular}

It shows in the table that rubber is more ductile then steel which ductile materials are materials that can be plastically twisted with no crack. They have the tendency to hold the deformation that occurs in the plastic region while the steel is brittle that when subjected to stress, it breaks without significant plastic deformation.

Below is the design of the rubber tire guardrails proposed to be used in the Skyways.

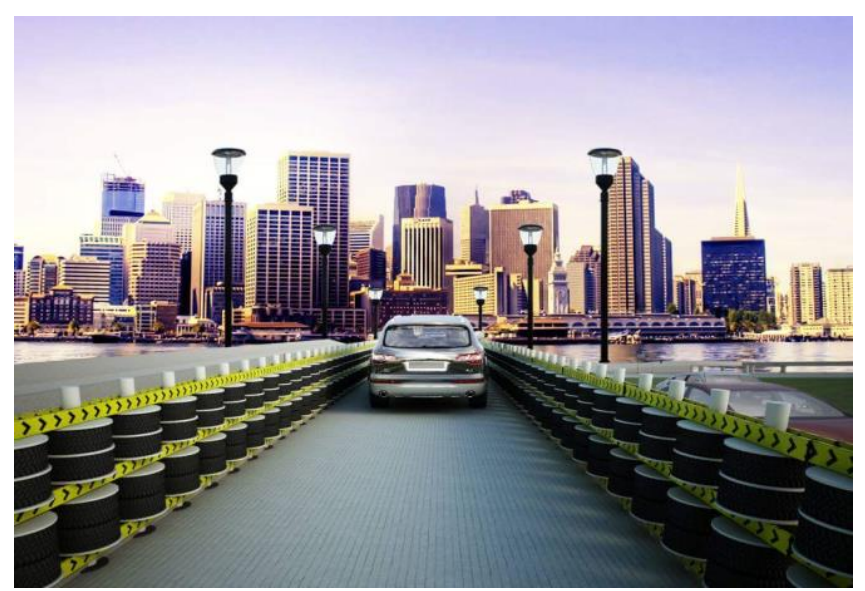

Figure 1. Design of an Improve Guardrails for South Super Skyways Using Steel and Rubber Tires

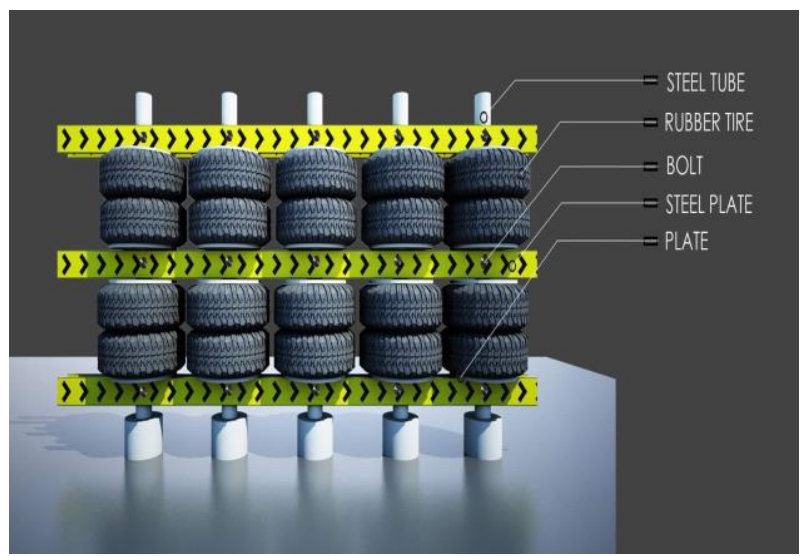

Figure 2. Components of the Proposed Design of Guardrail

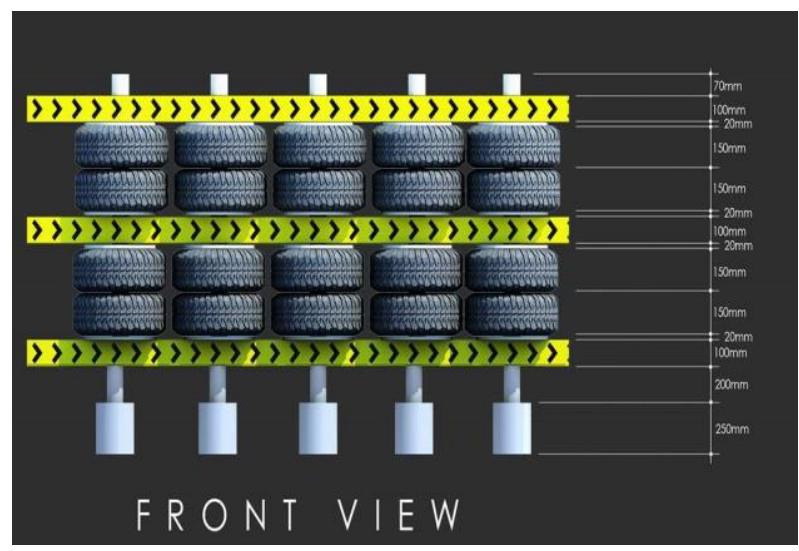

Figure 3. Front View 


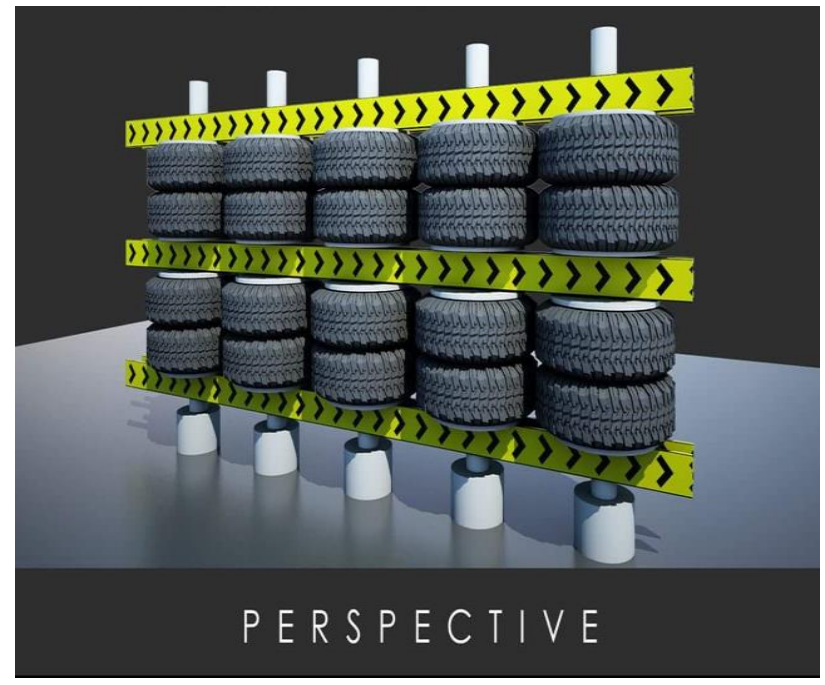

Figure 4. Perspective

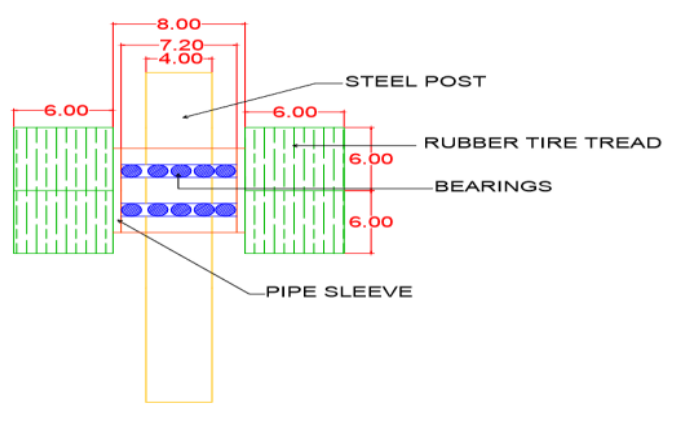

Figure 5. Cross Section

\section{CONCLUSIONS}

The proposed design of guardrails using rubber tires will reduce if not avoided damage in the vehicles thus reduces accident in the skyway. Since the properties of the rubber tire is more ductile than steel thus it can absorb and resist larger impact.

\section{REFERENCES}

[1] Zurbano, J. E.. MMDA Identifies 50 Accident-Prone Roads. The Manila Standard. 2016.

[2] Brizuela, M. B. Skyway Accident Raises a New Concerns Over Safety Standards. Philippine Daily Inquirer. 2015.

[3] Gabler, H. C., Gabauer, D. J., \& Tech, V. Opportunities for Reduction of Fatalities in Vehicle-Guardrail Collisions. Annual Proceedings /Association for the Advancement of Automotive Medicine, 51, 31-48. 2007.

[4] Burton, W.E. Engineering With Rubber. New York City, New York. The Maple Press Company. 1949

[5] Blow, C.M. Rubber Technology and Manufacture. Plastics and Rubber Institute. Butterworth Group . 1971.

[6] Tangonan. N.G). Rubber Production and Management in the Philippines. Quezon City: Department of Agriculture - Bureau of Agricultural Research (DA-BAR). 2012.

[7] Kim, J.K. \&Paglicawan, M.A. Effect of Devulcanizer on the Properties of Natural Rubber Vulcanizates. Philippine Journal of Science, 133(2), pp. 87-96. 2004.

[8] Mark, J.I., Burak, E. \& Roland, M.C. The Science and Technology of Rubber 4thedition. Academic Press: An imprint of Elsevier.Waltham, MA 02451, USA. 2013.

[9] Paglicawan, M. A. et al. Utilization of Waste Rubber Tire for Floo Tiles and Pavers. Material Science Division. DOST compound, Gen. Santos Ave., Bicutan, Taguig City. 2004. 